\title{
Effect of Viral Antigen Levels on the Serological Response and Efficiency of the Binary Ethylenimine-Inactivated Bluetongue Virus Serotype-16 Vaccine
}

\author{
Le Li*, Haisheng Miao*, Defang Liao*, Meiling Kou, Lin Gao, Huachun Li" \\ Yunnan Veterinary and Animal Science Institute, Kunming, China \\ Email: "Huachun_li@hotmail.com
}

How to cite this paper: Li, L., Miao, H.S., Liao, D.F., Kou, M.L., Gao, L. and Li, H.C. (2016) Effect of Viral Antigen Levels on the Serological Response and Efficiency of the Binary Ethylenimine-Inactivated Bluetongue Virus Serotype-16 Vaccine. World Journal of Vaccines, 6, 47-63.

http://dx.doi.org/10.4236/wjv.2016.64007

Received: October 9, 2016

Accepted: November 27, 2016

Published: November 30, 2016

Copyright $\odot 2016$ by authors and Scientific Research Publishing Inc. This work is licensed under the Creative Commons Attribution International License (CC BY 4.0).

http://creativecommons.org/licenses/by/4.0/

\begin{abstract}
Bluetongue (BT) is a serious hemorrhagic disease of ruminants caused by bluetongue virus (BTV). Inactive BTV vaccines have been successful in field trials in some areas, and inactivated vaccines are considered safer. However, information about the effect of the viral antigen level on the serological response and efficiency of the inactive BTV-16 vaccine is lacking. In the present study, the serological response and efficiency of the viral antigen concentration in the binary ethylenimine-inactivated Chinese BTV serotype-16 vaccine were investigated. The viral antigens in the viral suspension (VS) were quantified using a modified BTV AC-ELISA method. Four batches of vaccine containing $1,5,10$, and $50 \mu \mathrm{g} / \mathrm{ml}$ of viral antigen were generated from the VS. Four groups of naïve Chinese sheep were vaccinated with the different vaccine batches, and the serological response and vaccine efficiency were investigated before and after challenge infection. The vaccines containing 10 and $50 \mu \mathrm{g} / \mathrm{ml}$ of viral antigen induced significant ELISA and neutralizing antibody titers 14 days after vaccination, whereas the vaccines containing 1 and $5 \mu \mathrm{g} / \mathrm{ml}$ of viral antigen did not have these effects. A booster immunization at 21 days enhanced all groups' antibody titers; however, the increased titer was related to the viral antigen level. In contrast to the serological response, the viral antigen level of the vaccines did not have a significant effect on the vaccine efficiency. With the exception of one sheep from the $5 \mu \mathrm{g} / \mathrm{ml}$ viral antigen group, all vaccinated sheep from the four antigen level groups showed strong resistance to infection based on their clinical symptoms, rectal temperatures and viremia. Collectively, these data suggested that viral antigen levels from 1 to $50 \mu \mathrm{g} / \mathrm{ml}$
\end{abstract}

ॠThese authors contributed equally to the work. 
had a significant effect on the serological response of the animals but a limited effect on the vaccine efficiency. The BTV-16 vaccine containing $1 \mu \mathrm{g} / \mathrm{ml}$ of viral antigen was sufficient to achieve high efficiency, but only the vaccines with more than $10 \mu \mathrm{g} / \mathrm{ml}$ of antigen induced a significant antibody response. To obtain a better serological response, we suggest the use of vaccines with more than $10 \mu \mathrm{g} / \mathrm{ml}$ of viral antigen. The findings in the study will be useful for BTV vaccine production.

\section{Keywords}

Blue-Tongue Virus Serotype-16, Binary Ethylenimine-Inactivated Vaccine, Viral Antigen Level, Antibody, Efficiency

\section{Introduction}

Bluetongue (BT) is a serious hemorrhagic disease of ruminants caused by bluetongue virus (BTV). BTV is a non-contagious arthropod-borne viral pathogen that is a member of the Orbivirus genus and Reoviridae family [1] [2]. Currently, 26 serotypes have been identified worldwide [3]. A total of 13 BTV serotypes exist in BTV-enzootic areas of Yunnan province in China based on viral isolation and neutralization studies [4]. Serological investigations showed that BTV-16 was the dominant strain in the BTV-enzootic areas. BT mostly causes a mild disease or no obvious disease in the BTV-enzootic areas of Yunnan. However, a few serious disease cases have been identified. These serious cases are characterized by fever, facial edema, ulceration of the oral mucosa, congestion of the tongue and coronary band, debility, decreased production and variable mortality [2]. Recently, invasion of BTV in Mediterranean Europe and BTV-8 epizootics in Western and Central Europe has caused significant economic losses [5] [6]. $\mathrm{BT}$ is considered a re-emerging arboviral disease of ruminants in many countries [7] [8] [9]. Due to the importance of BT in China, the Chinese Ministry of Agriculture has launched programs on BT to study its prevention and control. Yunnan province is located in the southwest of China. The complicated nature and geographical environment of this province have resulted in closely linked BTVenzootic areas and BTV-free areas, which enhance the risk of cross-region BTV infection. From this perspective, the development of a BTV-16 vaccine that is effective against BTV infection for use in Yunnan province is essential.

Inactivated monovalent vaccines against BTV $-2,-4,-8$ and -16 have been used successfully in field trials [7] [10] [11] [12]. Inactivated vaccines are considered safer, and various risks have been associated with the use of live vaccines [13]. However, only low levels of specific antibodies are detected by C-ELISA, and nearly no virus neutralizing antibodies are observed in vaccinated sheep following the use of inactivated vaccines [12] [14]. Conversely, live attenuated BTV vaccines have been shown to induce effective and lasting immunity in sheep [9]; 
for instance, a modified live vaccine induced $98 \%$ of cattle to produce neutralizing antibodies one month after a single shot [15]. Moreover, a four-fold vaccine overdose in the cattle led to significantly higher C-ELISA antibody titers, and neutralizing antibodies could be detected as early as four weeks after the first vaccination [16]; this result indicates that the viral antigen level is important to the antibody response. However, the exact relationship between the viral antigen level and the serological response has not been reported. Antibodies are important for the prevention of BTV infection, and a negative correlation between the presence of neutralizing antibodies at the time of challenge infection and the subsequent incidence of clinical signs and viremia has been reported [17]. Furthermore, antibody analysis is useful under field conditions because evaluation of the immune response is limited to humoral immunity after millions of animals have been vaccinated [16]. Reports have indicated that the presence of neutralizing antibodies does not always correlate with the degree of protection [12]. These observations indicate that the vaccine should be judged by challenge infections rather than antibody analysis. However, information about the relationship between the antigen level and vaccine efficiency is lacking. The OIE manual has suggested the use of chromatography-purified and concentrated BTV antigens in vaccines via dilution in a buffer solution and the addition of adjuvants [1]. Therefore, knowledge of the relationship between the viral antigen and serological response and between the viral antigen and vaccine efficiency could be useful.

In the current study, the viral antigen level of the binary ethylenimine (BEI)inactivated oil-adjuvanted BTV-16 vaccine was determined via an AC-ELISA method. Vaccines containing viral antigen concentrations ranging from 1 to 50 $\mu \mathrm{g} / \mathrm{ml}$ were used to investigate the relationships between the viral antigen levels and the serological response and between the viral antigen levels and the vaccine efficiency.

\section{Material and Methods}

\subsection{Animals}

Thirty healthy 1.5-2-year-old naïve sheep weighing approximately $40 \mathrm{~kg}$ were purchased from the BT-free area (Xundian sheep breeding farm, Yunnan). The animals tested sero-negative by sero-neutralization (SNT) using BHK21 cells. The animals were randomly divided into five groups of 6 animals each, including four vaccine groups and one control group. All animals were maintained in insect-proof sheds. The experiments were performed in accordance with the research and ethical review committees of Yunnan Veterinary and Animal Science Institute.

\subsection{Virus}

BTV-16/DH/2015 is a BTV serotype 16 strain isolated from the blood of cattle in 
Dehong county of Yunnan province in 2015. A BHK21 virus passaged six times was used for the vaccine. A blood sample containing the same strain without passage in any cell line was injected into sheep to amplify the virus. Heparinized blood from the infected sheep was collected 7 days post-inoculation (dpi) and used for the challenge study. The infected blood used for the challenge was titrated by inoculation into embryonating chicken eggs (ECEs). The method used for titration was also used for the viremia analysis.

\subsection{Quantification of Viral Antigens in the Viral Suspension (VS)}

The viral antigens in the VS was quantified by comparison with purified BTV-16 antigen in a modified AC-ELISA. The purified BTV-16 antigens used for the comparison were collected from the $58 \%-60 \%$ sucrose gradient after centrifugation of the pre-condensed virus at 28,000 rpm with an sw40 rotor (Beckman, USA) for $4 \mathrm{~h}$. The purity of the purified BTV was verified by SDS-PAGE (10\%), and the viral protein concentration was determined by the BCA method according to the manufacturer's protocol.

The AC-ELISA method used for the quantification is briefly described below. An ELISA plate (Costar, USA) was coated with a polyclonal goat-anti-BTV antibody and incubated for $1 \mathrm{hr}$ at $37^{\circ} \mathrm{C}$. The plate was washed with PBST $(0.01 \mathrm{M}$, $\mathrm{pH}$ 7.6, containing 0.5\% TWEEN-20). Then, the VS and purified BTV-16 were added to duplicate wells with two-fold dilutions from $1 / 2$ to $1 / 256$ and incubated for $1 \mathrm{hr}$ at $37^{\circ} \mathrm{C}$. The plate was washed with PBST, and an anti-VP7 Mab was added to each well and incubated for $1 \mathrm{~h}$ at $37^{\circ} \mathrm{C}$. The plate was washed, and a goat-anti-mouse HRP-conjugated antibody was added and incubated for $0.5 \mathrm{hr}$ at $37^{\circ} \mathrm{C}$. Finally, the plate was washed carefully with PBST at least 5 times, and the TMB substrate was added. The color was allowed to develop for 10 minutes, and the reaction was stopped by adding $1 \mathrm{M}$ sulfuric acid. The optical density (OD) values were read on an ELISA plate reader (Thermo Multiskan Ascent, USA).

To obtain an accurate result, the linear development phase of the OD values was defined, and the linear logistic equation between the OD values and the viral antigen level was established. This equation was used to calculate the amount of viral antigens in the VS.

\subsection{BEI-Inactivated BTV-16 Vaccine Preparation and Immunization of Sheep}

The BEI-inactivated BTV-16 vaccine was prepared as previously described [10]. Briefly, BTV-16-infected BHK21 cells were harvested when they showed 90\% cytopathic effects. The suspension was freeze-thawed, sonicated and centrifuged to obtain the supernatant. A virus suspension with a titer greater than $10^{6}$ TCID50/50 $\mu$ l was used for the inactivation. The virus was inactivated with freshly prepared $0.02 \mathrm{M} \mathrm{BEI}$ for $48 \mathrm{~h}$ at $37^{\circ} \mathrm{C}$. The inactivation was stopped by 1 
M sodium thiosulfate at $4^{\circ} \mathrm{C}$, with a final concentration of $0.1 \mathrm{M}$ at the end of the incubation period. Following the sterility and innocuity tests [10], the whole viral antigen content in the viral suspension (VS) was determined by ELISA as described above. Then, the VS was diluted or concentrated to $1,5,10$ and $15 \mu \mathrm{g}$ of viral antigen $/ \mathrm{ml}$. The vaccine was adjuvanted by mixing thoroughly with an equal volume of an emulsifying agent (mineral oil, $2 \%$ Tween-80, and $1 \%$ thimerosal).

The sheep were divided into five groups ( $\mathrm{N}=6$ per group); four groups were immunized and one group was the control. Each immunized group received 1 $\mathrm{ml}$ of BEI-inactivated oil-adjuvanted BTV-16 vaccine with different viral antigen levels $(1,5,10$ and $15 \mu \mathrm{g}$ of viral antigen/ml). An equal quantity of vaccine was inoculated into the neck and posterior thigh by the intramuscular route. All vaccinated animals were re-vaccinated on the 21st day with a similar dose and route. The control group received PBS.

\subsection{Serology}

C-ELISA and SNT were used to survey the BTV antibody development of the immunized sheep. The C-ELISA was performed as previously described [1]. Briefly, a 96-well microplate was coated with sonicated cell culture antigen at $4^{\circ} \mathrm{C}$ overnight. Then, a serogroup-reactive anti-VP7 Mab was used as the competition antibody to compete with the sheep antibodies. Based on the recommended cut-off values, the samples were interpreted as positive if they showed an OD value less than $50 \%$ of the negative control. Sheep serum was diluted two-fold from $1 / 2$ to $1 / 256$ for the C-ELISA procedure. The titers were expressed as the final dilution of serum present in the dilution where $50 \%$ of the wells were positive.

The SNT was performed as follows. Starting from a 1:4 dilution, the sera were diluted in a two-fold dilution series across the plate using at least two rows of wells per serum sample in a $50 \mu \mathrm{l}$ volume. Approximately 100 TCID50 (50\% tissue culture infective dose) of the BTV-16 virus was added in a $50 \mu \mathrm{l}$ volume and mixed with the diluted serum. Approximately $10^{4}$ cells were added per well in a $100 \mu \mathrm{l}$ volume. After incubation for $4-6$ days, the results were read using an inverted microscope. The wells were scored for the degree of CPE observed. The titers were expressed as the final dilution of serum present in the serum/virus mixture where $50 \%$ of the wells were protected.

\subsection{Challenge}

The BTV-16 strain used in the study for the challenge infection was not passaged in any isolation system, which might induce a clinical BT disease milder than the natural disease. The virus retained moderate virulence as observed from the pilot study. Seven days after re-vaccination, both the immunized and naive groups were challenged by intradermal inoculation of $2 \mathrm{ml}$ of infected blood containing 
$10^{3} \mathrm{CEID} 50 / \mathrm{ml}$ of virus at multiple sites in the right neck. Blood samples were collected at $0,2,4,6,8,10$, and 14 days post-infection (dpi). The clinical signs and rectal temperatures were recorded daily following challenge.

\subsection{Clinical Observations}

The average clinical scores (ACS) were previously described and were used with a few modifications [10] [18]. From $1-14$ dpi, the ACSs of the challenged animals were calculated for fever, mouth lesions, foot lesions and respiratory signs. The details are given below:

(a) Fever score-fever readings above $40^{\circ} \mathrm{C}$ from 2 to $14 \mathrm{dpi}$ were taken as the cumulative total for each animal and averaged to obtain the fever ACS.

(b) Mouth lesion score-mouth lesions were scored on a scale of 0 - 4 in each animal depending on the severity and averaged to obtain the mouth ACS.

(c) Foot lesion score-foot lesions were scored on a scale of 0 - 4 in each animal depending on the severity and averaged to obtain the foot ACS.

(d) Respiratory score-nasal discharge (serous to bloody discharge) and respiratory distress were scored on a scale of $0-4$ depending on the severity and averaged to obtain the respiratory ACS.

\subsection{Viremia Analysis}

\subsubsection{Viremia Analysis by Titration of Infected Blood}

Heparinized blood collected aseptically from each sheep was briefly titrated through ECEs. The ECEs were inoculated with a series of 10 -fold dilutions of infected blood. The chicken embryos were incubated for 7 days at $33.5^{\circ} \mathrm{C}$. Tissues from the embryos that died between 2 and 7 dpi were collected, and the presence of BTV was confirmed using a Bluetongue antigen capture ELISA (BTACE) based on a monoclonal antibody to the BTV core protein VP7 [19]. The results were expressed as the chicken embryo infections dose (CEID50), which was calculated using the method of Reed and Muench [20].

\subsubsection{Quantification of BTV RNA in the Blood by Quantitative RT-PCR}

Total RNA was extracted from the heparinized samples using the MagMAXTM -96 Blood RNA Isolation kit (Am1837) on the MagMAXTM express machine (Ambion, USA). The primers used to amplify the NS1 segment of BTV-16 were previously reported [21]. The viral genome was estimated by quantitative realtime PCR using the Ambion Fast7500 system (Applied Biosystems, USA). Briefly, a real-time RT-PCR (qRT-PCR) for BTV NS1 was performed using the ABI Am1005 AgPath-ID ${ }^{\text {ma }}$ One-Step RT-PCR Kit (Ambion, USA) with a $2 \mu$ RNA sample in a total volume of $20 \mu$ including PCR master mix with $6 \mathrm{mM} \mathrm{MgCl}$, $0.5 \mu \mathrm{M}$ of each PCR primer and $0.2 \mu \mathrm{M}$ of each hybridization probe. The RT-PCR program consisted of $10 \mathrm{~min}$ of reverse transcription at $45^{\circ} \mathrm{C}, 10 \mathrm{~min}$ of denaturation at $95^{\circ} \mathrm{C}, 45$ cycles of a 15 second denaturation at $95^{\circ} \mathrm{C}, 20$ seconds of annealing and 20 seconds extension at $65^{\circ} \mathrm{C}$. Fluorescence was measured at 
the end of each annealing step.

BTV RNA in the blood was quantified using previously described methods [22].

Total BTV-16 RNA was extracted from infected BHK-21 cells with viral titers greater than $10^{6}$ TCID50 $(50 \mu \mathrm{l})$. Cellular ssRNA was removed with $2 \mathrm{M} \mathrm{LiCl}$ [23] [24] to obtain pure viral dsRNA, which was analyzed by spectrophotometry. A total of $1 \mu \mathrm{g}$ of purified BTV RNA was converted to cDNA using random primers with the Reverse Transcription System (Promega, USA) and used for standard dilution curve preparation. Ten-fold serial dilutions of known copies of cDNA and their corresponding CT values were used to generate a standard $\log _{10}$ dilution curve with a correlation coefficient of 0.97 . An increase of 2.0 cycles for every $\log _{10}$ decrease of input RNA was shown based on the slope of the regression line. Quantification was accomplished by comparing the CT values of each test sample with the standard curve drawn on the same reaction.

\subsection{Statistical Analysis}

All statistical analyses were performed with SPSS 17.0. The $\log 10$ of the viral antigen dilution and the OD reading were analyzed by linear-regression analysis to generate a linear equation. The results of the viremic titers in the naive and immunized animals were compared using a non-parametric Mann-Whitney test. A $P$-value $<0.05$ was considered significant.

\section{Results}

\subsection{Quantification of Viral Antigens in the VS}

The BTV AC-ELISA results are expressed as OD values that depend on the viral antigen concentration. A strong linear correlation was observed between the logarithm of the viral antigen concentration and the OD values at the appropriate stage. In this study, the OD values dropped from 1.8 to 1.2 accompanied by a purified antigen dilution drop from $1 / 32$ to $1 / 256$ (Table 1), indicating an obvious linear phase. The linear regression analysis showed a strong linear relationship $\left(R^{2}=0.992\right)$. Then, the data were used to establish a linear logistic equation between the $\mathrm{OD}$ value and the logarithmic antigen concentration. The equation was $\log 2\left(\mathrm{Y}_{\text {Antigen }}\right)=4.5 \mathrm{X}_{\mathrm{OD}}-6.79$ in the study (Figure 1$)$. The OD values of the sample within the linear phase were selected to calculate the amount of viral antigen. The average amount of viral antigen in the VS was determined based on the results of 3 independent experiments. In our study, $3 \pm 0.21 \mu \mathrm{g} / \mathrm{ml}$ of viral antigen was obtained in the VS. Then, the virus in the VS was concentrated by PEG6000 and diluted with PBS to final vaccine concentrations of $1,5,10$, and 50 $\mu \mathrm{g} / \mathrm{ml}$ of viral antigen.

\subsection{Viral Antigen Level and Serological Response}

Sera from the immunized and control animals were collected weekly after 
Table 1. Definition of the linear phase of the OD and $\log 2$ dilution (shown in gray).

\begin{tabular}{ccccccc}
\hline Purified BTV antigen & \multicolumn{5}{c}{ VS } \\
\hline Dilution & $\mu \mathrm{g} / \mathrm{ml}$ & OD & & Dilution & OD & \\
\hline 1 & 103.0 & 1.8194 & 1.8093 & 1 & 1.7751 & 1.7978 \\
$1 / 2$ & 51.5 & 1.8802 & 1.8682 & $1 / 2$ & 1.7491 & 1.7563 \\
$1 / 4$ & 25.8 & 1.8736 & 1.8725 & $1 / 4$ & 1.4817 & 1.4265 \\
$1 / 8$ & 12.9 & 1.8681 & 1.8709 & $1 / 8$ & 1.2809 & 1.2549 \\
$1 / 16$ & 6.4 & 1.8627 & 1.8607 & BLANK & 0.0391 & 0.0241 \\
$1 / 32 \mathrm{a}$ & 3.2 & 1.8528 & 1.8621 & BLANK & 0.0403 & 0.0453 \\
$1 / 64$ & 1.6 & 1.6521 & 1.6786 & BLANK & 0.0426 & 0.0398 \\
$1 / 128$ & 0.8 & 1.4477 & 1.4709 & BLANK & 0.0389 & 0.0405 \\
$1 / 256$ & 0.4 & 1.1845 & 1.1939 & & & \\
\hline
\end{tabular}

aThe gray color shows the linear phase of the OD values.

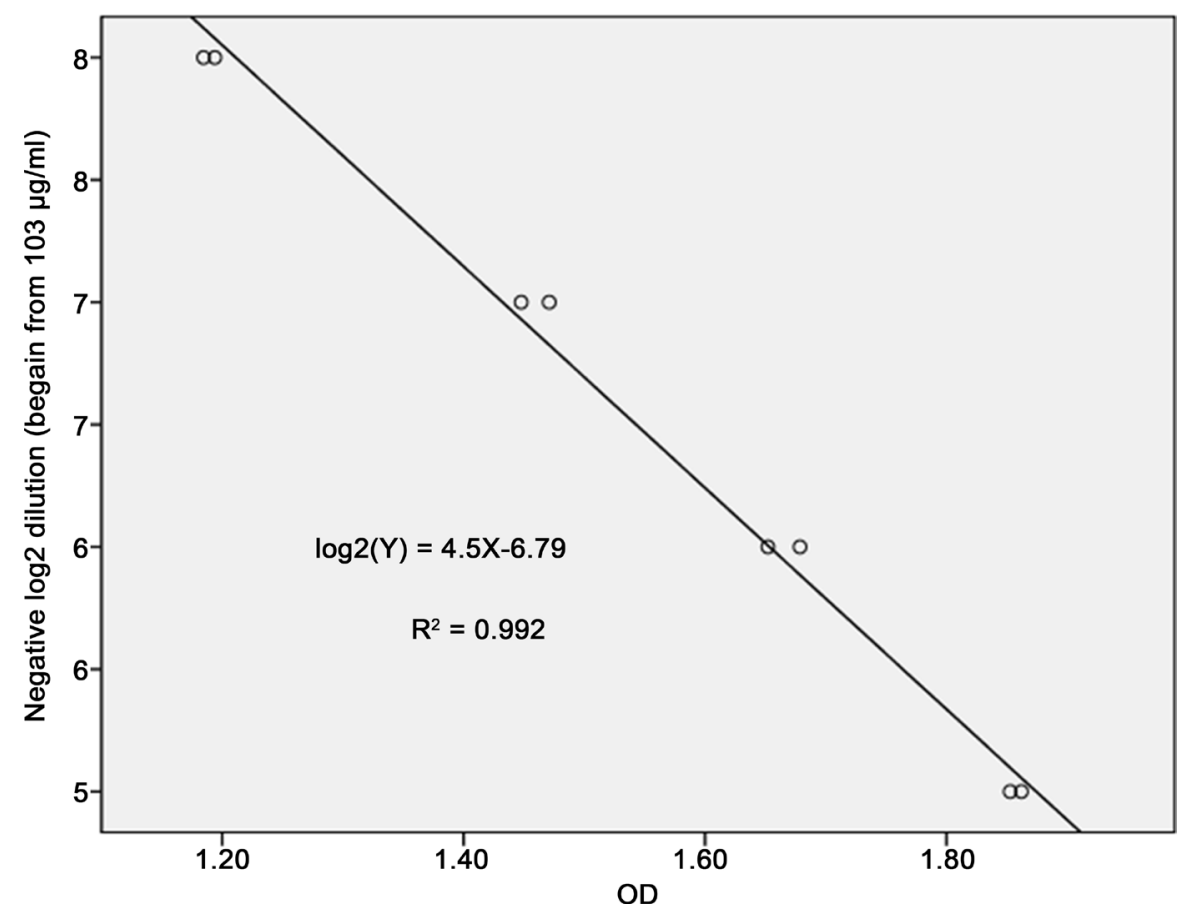

Figure 1. Linear regressive analysis of the OD values and negative $\log 2$ dilutions of purified BTV-16.

vaccination for serology surveillance by C-ELISA and SNT. The kinetics of the mean antibody titers $(\mathrm{N}=6)$ in the C-ELISA and SNT assays showed almost the same pattern (Figure 2). The $1 \mu \mathrm{g} / \mathrm{ml}$ group did not demonstrate a significant antibody yield until one week after the booster immunization. The $5 \mu \mathrm{g} / \mathrm{ml}$ group exhibited an antibody yield after the first vaccination, but the titer was low compared with the $10 \mu \mathrm{g} / \mathrm{ml}$ and $50 \mu \mathrm{g} / \mathrm{ml}$ groups $(P<0.05)$. No significant difference in the antibody titers was detected between the $10 \mu \mathrm{g} / \mathrm{ml}$ and $50 \mu \mathrm{g} / \mathrm{ml}$ 


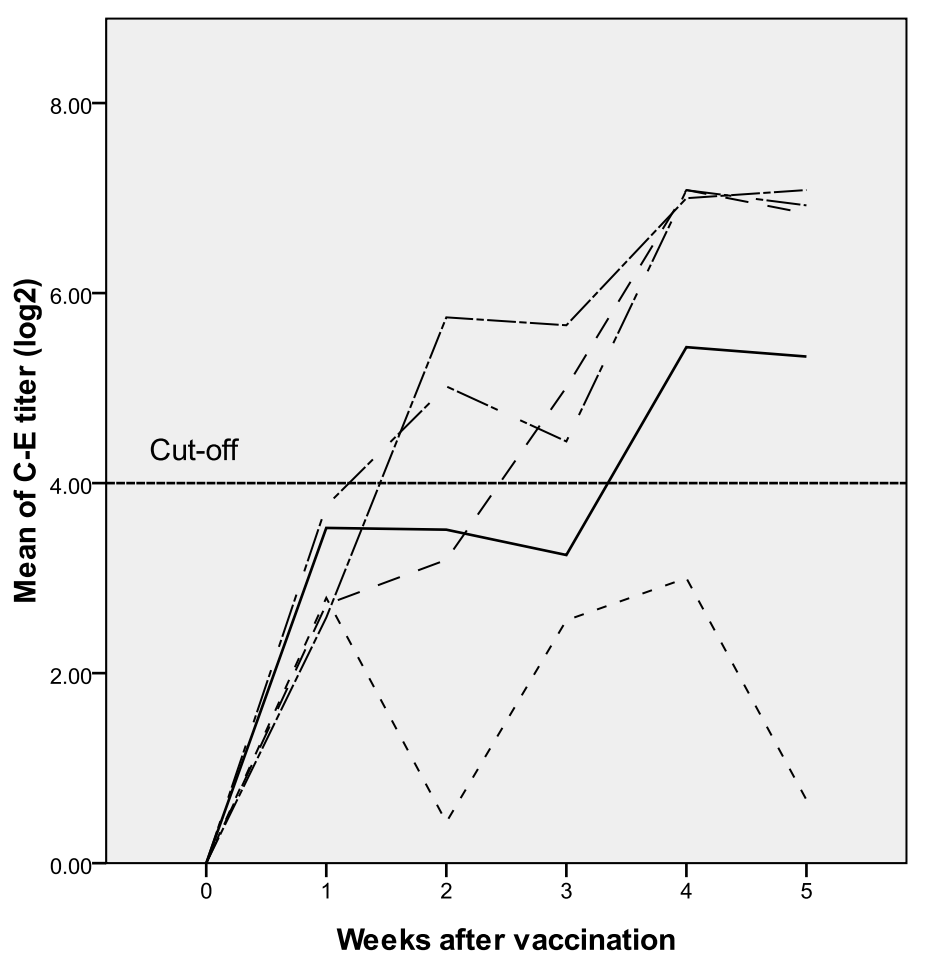

$$
\begin{aligned}
& -1 \mu \mathrm{g} / \mathrm{mi} \\
& -5 \mu \mathrm{g} / \mathrm{ml} \\
& -10 \mu \mathrm{g} / \mathrm{ml} \\
& -50 \mu \mathrm{g} / \mathrm{m} \\
& -- \text { Control }
\end{aligned}
$$

(a)

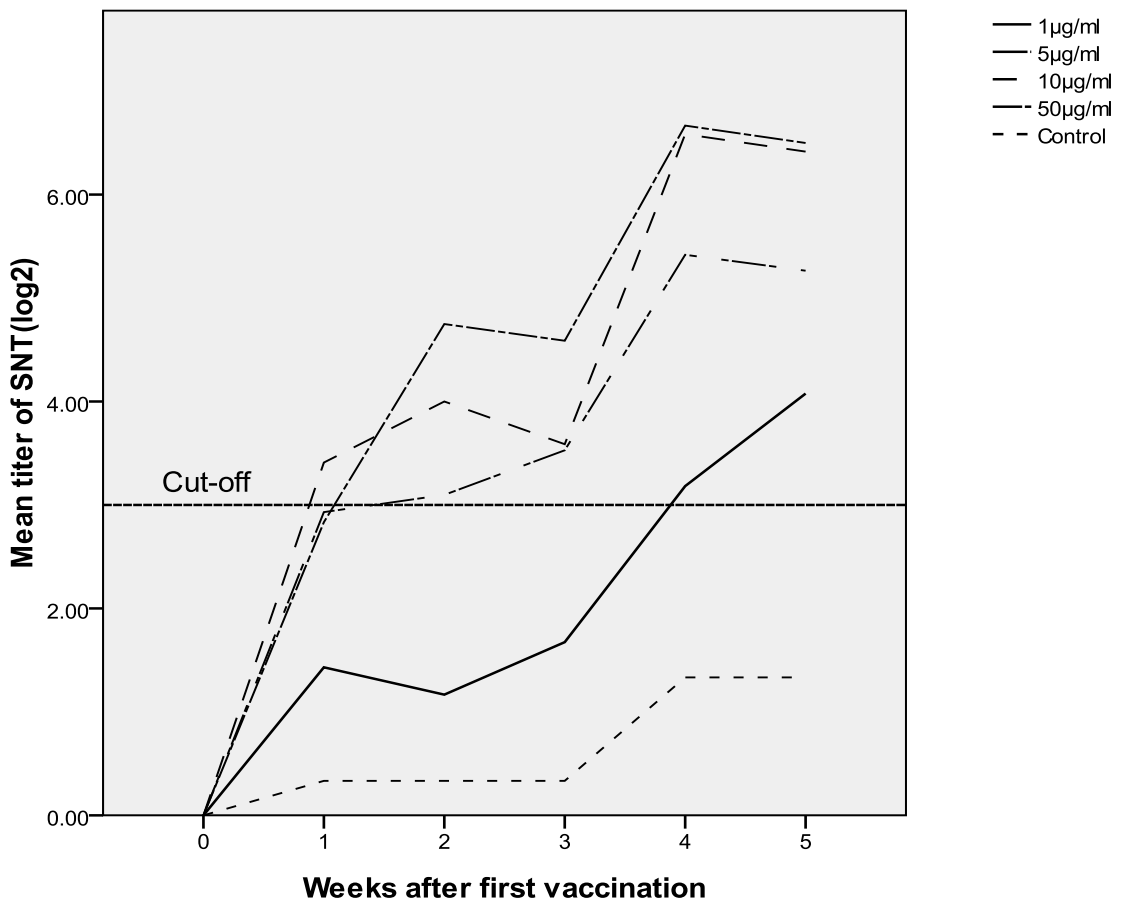

(b)

Figure 2. Kinetics of the C-ELISA (a) and SNT (b) antibody titers to BTV-16 during the course of the experiment. The starts indicate the first vaccination time, and the second vaccination was administered 3 weeks after the $1^{\text {st }}$ vaccination. The dashed line indicates the cut off titer value (titer $\geq 4$ for C-ELISA and titer $\geq 3$ for SNT), which was calculated as the mean titer \pm 3 SD of the negative sera $(n=60)$. 
groups $(P>0.05)$. The antibody response of the animals in the $1 \mu \mathrm{g} / \mathrm{ml}$ and 5 $\mu \mathrm{g} / \mathrm{ml}$ groups was diverse, with some animals not exhibiting a significant antibody response even after the second vaccination (Table 2). The booster immunization 21 days after the first immunization enhanced the ELISA and SNT antibody titers in the 4 groups. However, the boosted ELISA and SNT titers of the $1 \mu \mathrm{g} / \mathrm{ml}$ group were significantly lower than the titers in the other groups $(P<$ 0.01 ), and no difference was detected in the boosted SNT titers of the 10 and 50 $\mu \mathrm{g} / \mathrm{ml}$ groups.

\subsection{Viremia Analysis in Challenge Infection}

The viremia of all immunized groups in the challenge infection was assessed by virus inoculation and qRT-PCR. Sero-negative sheep were immunized twice at 3 week intervals and challenged with homologous BTV-16. The virus inoculation results were expressed as CEID50 by inoculation of ECEs with a series of whole blood dilutions, and the viral RNA copies in the same blood samples were monitored by BTV qRT-PCR. The CEID50 and viral copies of the control sheep were significantly higher $(P<0.01)$ from 4 to $16 \mathrm{dpi}$ compared to the immunized sheep (Table 3, Table 4). Exceptionally, one control sheep maintained an undetectable CEID50 during the experiment, although viral RNA was detected from 4 DPI. Conversely, immunized sheep from the 1,10 , and $50 \mu \mathrm{g} / \mathrm{ml}$ antigen level groups showed viral titers and viral RNA copies below the detection limit during the test period. Only one immunized sheep from the $5 \mu \mathrm{g} / \mathrm{ml}$ group had a detectable viral titer and viral RNA copies from 4 to $16 \mathrm{DPI}$; this animal also had rising temperature, but with no other clinical symptoms were observed. No obvious relationship was found between the antigen level and viremia.

\subsection{Clinical Disease Analysis in Challenge Infection}

Following challenge, the animals in the naive and four antigen level vaccine

Table 2. Number of animals with C-ELISA and SNT titers above the cut-off $(1 / 16$ and $1 / 8)$.

\begin{tabular}{cccccccc}
\hline \multirow{2}{*}{ Method } & Group & \multicolumn{6}{c}{ Weeks after vaccination } \\
\cline { 2 - 8 } C-ELISA & $(6$ animals each $)$ & $0 \mathrm{w}$ & $1 \mathrm{w}$ & $2 \mathrm{w}$ & $3 \mathrm{w}^{\mathrm{a}}$ & $4 \mathrm{w}$ & $5 \mathrm{w}$ \\
& $1 \mu \mathrm{g} / \mathrm{ml}$ & 0 & 2 & 3 & 2 & 5 & 5 \\
& $5 \mu \mathrm{g} / \mathrm{ml}$ & 0 & 2 & 5 & 5 & 6 & 6 \\
& $10 \mu \mathrm{g} / \mathrm{ml}$ & 0 & 0 & 5 & 6 & 6 & 6 \\
$5 N \mu \mathrm{g} / \mathrm{ml}$ & 0 & 0 & 5 & 5 & 6 & 6 \\
& $1 \mu \mathrm{g} / \mathrm{ml}$ & 0 & 0 & 1 & 2 & 3 & 5 \\
& $5 \mu \mathrm{g} / \mathrm{ml}$ & 0 & 3 & 3 & 4 & 6 & 5 \\
& $10 \mu \mathrm{g} / \mathrm{ml}$ & 0 & 5 & 6 & 6 & 6 & 6 \\
& $50 \mu \mathrm{g} / \mathrm{ml}$ & 0 & 5 & 6 & 6 & 6 & 6 \\
\hline
\end{tabular}

${ }^{\mathrm{a} S e c o n d ~ v a c c i n a t i o n . ~}$ 
Table 3. BTV viremia in blood samples (ECE inoculation).

\begin{tabular}{|c|c|c|c|c|c|c|c|c|c|c|}
\hline \multirow{2}{*}{ Group } & \multirow{2}{*}{ Sheep No. } & \multicolumn{9}{|c|}{ Viremia (CEID50) } \\
\hline & & $0 \mathrm{dpi}$ & $2 \mathrm{dpi}$ & $4 \mathrm{dpi}$ & $6 \mathrm{dpi}$ & $8 \mathrm{dpi}$ & $10 \mathrm{dpi}$ & $12 \mathrm{dpi}$ & $14 \mathrm{dpi}$ & $16 \mathrm{dpi}$ \\
\hline $1 \mu \mathrm{g} / \mathrm{dose}$ & $1-6$ & $\mathrm{NVD}^{\mathrm{a}}$ & NVD & NVD & NVD & NVD & NVD & NVD & NVD & NVD \\
\hline \multirow[t]{6}{*}{$5 \mu \mathrm{g} / \mathrm{dose}$} & 7 & NVD & NVD & NVD & NVD & NVD & NVD & NVD & NVD & NVD \\
\hline & 8 & NVD & NVD & NVD & NVD & NVD & NVD & NVD & NVD & NVD \\
\hline & 9 & NVD & NVD & NVD & NVD & NVD & NVD & NVD & NVD & NVD \\
\hline & 10 & NVD & NVD & NVD & NVD & NVD & NVD & NVD & NVD & NVD \\
\hline & 11 & NVD & NVD & 1.83 & 3.17 & 3.17 & 2.17 & 2.17 & 1.83 & 1.83 \\
\hline & 12 & NVD & NVD & NVD & NVD & NVD & NVD & NVD & NVD & NVD \\
\hline $10 \mu \mathrm{g} /$ dose & $13-18$ & NVD & NVD & NVD & NVD & NVD & NVD & NVD & NVD & NVD \\
\hline $50 \mu \mathrm{g} /$ dose & $19-24$ & NVD & NVD & NVD & NVD & NVD & NVD & NVD & NVD & NVD \\
\hline \multirow[t]{6}{*}{ Naive control } & 25 & NVD & 1.17 & 2.17 & 2.83 & 2.83 & 3.5 & 2.87 & 2.87 & 2.87 \\
\hline & 26 & NVD & NVD & 2.17 & 3.5 & 3.5 & 2.17 & 2.17 & 1.83 & 1.83 \\
\hline & 27 & NVD & NVD & 1.5 & 3.17 & 3.17 & 1.83 & 1.83 & 1.5 & 0.83 \\
\hline & 28 & NVD & NVD & 1.83 & 3.17 & 3.17 & 1.83 & 1.83 & 1.83 & 1.83 \\
\hline & 29 & NVD & NVD & NVD & NVD & 1.83 & 2.17 & 1.83 & 0.83 & 0.83 \\
\hline & 30 & NVD & NVD & NVD & NVD & NVD & NVD & NVD & NVD & NVD \\
\hline
\end{tabular}

${ }^{a}$ No viral load detected (NVD).

Table 4. BTV viremia in blood samples (qRT-PCR).

\begin{tabular}{|c|c|c|c|c|c|c|c|c|c|c|}
\hline \multirow[t]{2}{*}{ Group } & \multirow[t]{2}{*}{ Sheep } & \multicolumn{9}{|c|}{ Viremia ( $\log 10$ BTV copies/2 $\mu$ g blood RNA) } \\
\hline & & 0 dpi & $2 \mathrm{dpi}$ & $4 \mathrm{dpi}$ & $6 \mathrm{dpi}$ & $8 \mathrm{dpi}$ & $10 \mathrm{dpi}$ & $12 \mathrm{dpi}$ & $14 \mathrm{dpi}$ & $16 \mathrm{dpi}$ \\
\hline $1 \mu \mathrm{g} /$ dose & $1-6$ & $\mathrm{NVD}^{\mathrm{a}}$ & NVD & NVD & NVD & NVD & NVD & NVD & NVD & NVD \\
\hline \multirow[t]{6}{*}{$5 \mu \mathrm{g} /$ dose } & 7 & NVD & NVD & NVD & NVD & NVD & NVD & NVD & NVD & NVD \\
\hline & 8 & NVD & NVD & NVD & NVD & NVD & NVD & NVD & NVD & NVD \\
\hline & 9 & NVD & NVD & NVD & NVD & NVD & NVD & NVD & NVD & NVD \\
\hline & 10 & NVD & NVD & NVD & NVD & NVD & NVD & NVD & NVD & NVD \\
\hline & 11 & NVD & NVD & 3.01 & 5.12 & 5.12 & 4.21 & 4.82 & 4.52 & 4.21 \\
\hline & 12 & NVD & NVD & NVD & NVD & NVD & NVD & NVD & NVD & NVD \\
\hline $10 \mu \mathrm{g} / \mathrm{dose}$ & $13-18$ & NVD & NVD & NVD & NVD & NVD & NVD & NVD & NVD & NVD \\
\hline $50 \mu \mathrm{g} / \mathrm{dose}$ & $19-24$ & NVD & NVD & NVD & NVD & NVD & NVD & NVD & NVD & NVD \\
\hline \multirow[t]{6}{*}{ Naive control } & 25 & NVD & NVD & 5.42 & 5.42 & 5.42 & 5.12 & 4.52 & 4.21 & 4.52 \\
\hline & 26 & NVD & NVD & 3.91 & 5.42 & 5.12 & 5.12 & 4.82 & 4.82 & 4.82 \\
\hline & 27 & NVD & NVD & NVD & 5.72 & 4.82 & 5.12 & 4.82 & 4.82 & 4.82 \\
\hline & 28 & NVD & NVD & 3.91 & 5.42 & 5.42 & 5.12 & 4.52 & 5.12 & 4.82 \\
\hline & 29 & NVD & NVD & 5.72 & 4.52 & 4.21 & 5.12 & 4.52 & 4.82 & 4.82 \\
\hline & 30 & NVD & NVD & 5.12 & 4.21 & 4.52 & 3.61 & 4.21 & 3.91 & 4.21 \\
\hline
\end{tabular}

${ }^{a}$ No viral load detected (NVD). 
groups were monitored daily for rectal temperatures and clinical manifestations. All naive animals showed significantly higher temperatures $\left(>40.0^{\circ} \mathrm{C}\right)(P<0.01)$ for a prolonged period (6 - $10 \mathrm{DPI})$ compared to the immunized sheep. However, only mouth lesions and slight respiratory signs were observed in the naive animals. Five of these naive sheep developed mouth lesions characterized by oral erosion and cyanosis of the tongue, and three of these sheep showed respiratory signs limited to transient mild serous discharge without any signs of respiratory distress. In contrast, none of the sheep from the 1,10 , and $50 \mu \mathrm{g} / \mathrm{ml}$ antigen level groups showed fever and other clinical symptoms; one sheep from the $5 \mu \mathrm{g} / \mathrm{ml}$ group exhibited a rise in the rectal temperature but did not show any other clinical symptoms (Figure 3). None of the vaccinated animal developed any mouth lesions or respiratory signs. No obvious relationship was found between the antigen level and the clinical disease score in the challenge infection.

\section{Discussion}

BTV-16 is the dominant strain that is prevalent in BTV-enzootic areas of China. Although mild to moderate BT disease has been observed in local sheep associated with infection, this virus still causes serious economic losses in the large sheep flocks in the area, and causes serious BT disease in exotic sheep imported for breed improvement. In the present investigation, BEI-inactivated oil-adjuvanted BTV-16 was found to be useful against infection with homologous BTV-16.

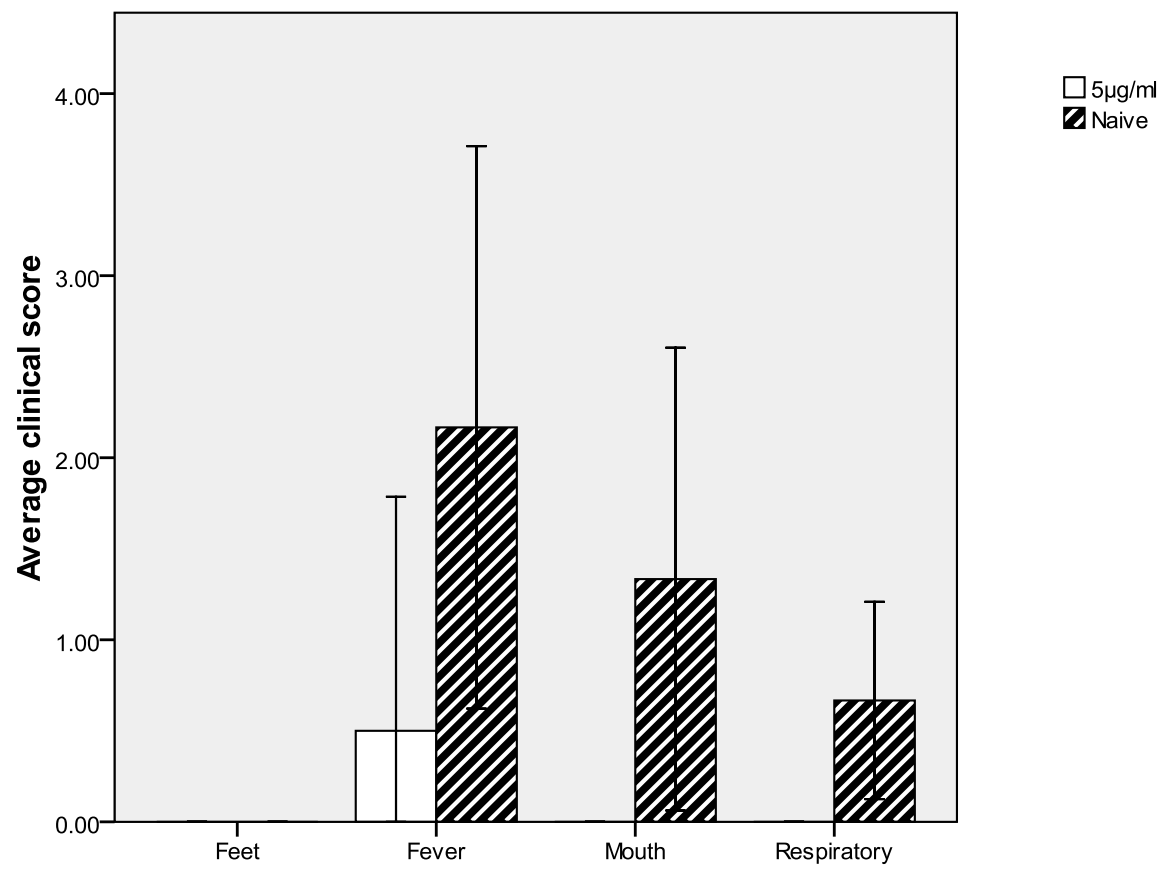

Figure 3. Inactivated BTV-16 vaccination considerably reduces clinical signs and lesions in immunized sheep following the challenge infection. The average clinical score was calculated in the naive and $5 \mu \mathrm{g} / \mathrm{ml}$ group from 1 - 14 DPI for fever, mouth lesions, foot lesions and respiratory signs. The graph represents the mean \pm S.D. values $(n=6)$. 
Low levels of antibodies in the serum samples of cattle and sheep are associated with the use of inactive vaccines [9] [15]. However, an increase in the vaccine dose in cattle clearly led to higher ELISA titers [16], indicating that a higher viral antigen level could induce a better serological response. In the study, we used vaccines containing 1 to $50 \mu \mathrm{g} / \mathrm{ml}$ of antigen and showed that the vaccine with the $1 \mu \mathrm{g} / \mathrm{ml}$ antigen level poorly induced antibody production, the $5 \mu \mathrm{g} / \mathrm{ml}$ antigen level induced intermediate antibody production, and the 10 and 50 $\mu \mathrm{g} / \mathrm{ml}$ antigen levels induced good ELISA and SNT antibody results. No difference was observed between the vaccines with the 10 and $50 \mu \mathrm{g} / \mathrm{ml}$ antigen levels. A boost immunization was useful for improving the antibody level, but the boost in antibody production in the $1 \mu \mathrm{g} / \mathrm{ml}$ antigen level group was still significantly lower compared with the other groups.

Neutralizing antibodies are important for the prevention of BT disease. A negative correlation was found between the presence of neutralizing antibodies at the time of challenge infection and the subsequent incidence of clinical signs and viremia [17]. Other studies showed that the presence of neutralizing antibodies did not always correlate with the degree of protection [12]. Vaccine-induced protection was also observed in the absence of detectable BTV neutralizing antibody levels [25]. A similar observation was found in this study. The vaccine containing $1 \mu \mathrm{g} / \mathrm{ml}$ of viral antigen poorly induced neutralizing antibodies but provided good protection for the animals against the challenge infection. This result may be due to specific cellular involvement in the defense against BTV, with the ability to cross-protect against other serotypes [23] [26]. However, the cross-protection by the specific cellular response may have been related to conserved proteins such as NS1 and thus only contributed partial protection. For more efficient protection, more specific neutralizing antibodies may be needed. In our study, a sheep from the $5 \mu \mathrm{g} / \mathrm{ml}$ antigen level group failed in the challenge infection, which might indicate that a higher antibody titer was needed. The failure of one sheep in the challenge infection did not represent statistical significance compared with the other groups; however, a vaccine containing a viral antigen concentration greater than $10 \mu \mathrm{g} / \mathrm{ml}$ may be better to avoid random immune failure and achieve a better antibody response.

OIE suggests purification should be used in inactive vaccine preparation [1]. This procedure is performed by chromatography; then, the inactivated virus is concentrated by ultrafiltration and stored before proceeding to vaccination. Chromatography is a good method but requires expensive equipment, which makes this approach impossible in many laboratories. ELISA quantification has been used for other viruses [27]. This method has good repeatability and reliability. However, because ELISA quantification is an indirect method, other factors should be considered in the quantification procedure. Importantly, the purity of the standard antigen used for comparison has a huge influence on the quantification accuracy. In this study, the BTV antigen was purified through a 
continuous sucrose gradient, and the purity was demonstrated by SDS-PAGE to have possibly improved the level of accuracy.

\section{Conclusion}

The development of vaccines that are easy to standardize through antigenic quantification would offer a better strategy for improving regional protection against BTV infection. A vaccine with sufficient antigen to induce neutralizing antibodies is likely to provide better protection against the infection. Although further evaluation of the vaccine is required under field conditions, the present findings suggest that viral antigen levels from 1 to $50 \mu \mathrm{g} / \mathrm{ml}$ in an inactive BTV-16 vaccine have a significant effect on the serological response. The vaccine containing $1 \mu \mathrm{g} / \mathrm{ml}$ was sufficient to induce high protection; however, to obtain a better serological response, we recommend using a vaccine with more than 10 $\mu \mathrm{g} / \mathrm{ml}$ of viral antigen.

\section{Acknowledgements}

Le Li, Miao Heisheng and Liao Defeng contributed equally to the study. The authors gratefully acknowledge P.D. Kirkland from the Elizabeth Macarthur Agricultural Institute (EMAI) of Australia for providing the monoclonal antibody to BTV core protein VP7.

\section{Funding}

This study was part of the project "Development of control methods for key vector-borne diseases of sheep and ox in China", which was supported by the Ministry of Agriculture of the PR of China.

\section{References}

[1] OIE (2016) Bluetongue. In: Terrestrial Animal Health Code, Web Version, Office International des Epizootis, Paris, Chapter 2.1.3.

http://www.oie.int/fileadmin/Home/eng/Health_standards/tahm/2.01.03_BLUETO NGUE.pdf

[2] Maclachlan, N.J., Drew, C.P., Darpel, K.E. and Worwa, G. (2009) The Pathology and Pathogenesis of Bluetongue. Journal of Comparative Pathology, 141, 1-16. http://www.sciencedirect.com/science/article/pii/S0021997509000498 https://doi.org/10.1016/j.jcpa.2009.04.003

[3] Maan, S., Maan, N.S., Nomikou, K., Batten, C., Antony, F., Belaganahalli, M.N., Samy, A.M., Reda, A.A., Al-Rashid, S.A., El Batel, M., Oura, C.A. and Mertens, P.P. (2011) Novel Bluetongue Virus Serotype from Kuwait. Emergency Infectious Disease, 17, 886-889. http://wwwnc.cdc.gov/eid/article/17/5/10-1742_article

[4] Kirkland, P.D., Zhang, N. and Hawkes, R.A. (2002) Studies on the Epidemiology of Bluetongue Virus in China. Epidemiology and Infection, 128, 257-263. https://www.cambridge.org/core/journals/epidemiology-and-infection/article/studi es-on-the-epidemiology-of-bluetongue-virus-in-china/6082A8D082D14A84507641 3D9618B37A 
https://doi.org/10.1017/S0950268801006525

[5] Saegerman, C., Berkvens, D. and Mellor, P.S. (2008) Bluetongue Epidemiology in the European Union. Emergency Infectious Disease, 14, 539-544.

http://193.190.239.98/handle/10390/2256

https://doi.org/10.3201/eid1404.071441

[6] Eschbaumer, M., Hoffmann, B., Konig, P., Teifke, J.P., Gethmann, J.M. and Conraths, F.J. (2009) Efficacy of Three Inactivated Vaccines against Bluetongue Virus Serotype 8 in Sheep. Vaccine, 27, 4169-4175.

http://www.sciencedirect.com/science/article/pii/S0264410X09006100 https://doi.org/10.1016/j.vaccine.2009.04.056

[7] Backx, A., Heutink, C.G., van Rooij, E.M. and van Rijn, P.A. (2007) Clinical Signs of Bluetongue Virus Serotype 8 Infection in Sheep and Goats. Veterinary Record, 161, 591-592.

https://www.researchgate.net/publication/5881460_Clinical_signs_of_bluetongue_v irus_serotype_8_infection_in_sheep_and_goats https://doi.org/10.1136/vr.161.17.591

[8] Darpel, K.E., Batten, C.A., Veronesi, E., Shaw, A.E., Anthony, S., Bachanek-Bankowska, K., Kgosana, L., Bin-Tarif, A., Carpenter, S., Muller-Doblies, U.U., Takamatsu, H.H., Mellor, P.S., Mertens, P.P. and Oura, C.A. (2007) Clinical Signs and Pathology Shown by British Sheep and Cattle Infected with Bluetongue Virus Serotype 8 Derived from the 2006 Outbreak in Northern Europe. Veterinary Record, 161, 253-261. http://www.ncbi.nlm.nih.gov/pubmed/17720961

[9] Verwoerd, D.W. and Erasmus, B.J. (2004) Bluetongue. In: Coetzer, J.A.W. and Tustin, R.C., Eds., Infectious Diseases of Livestock, 2nd Edition, Oxford University Press, Cape Town, 1201-1220.

[10] Hamers, C., Rehbein, S., Hudelet, P., Blanchet, M., Lapostolle, B. and Cariou, C. (2009) Protective Duration of Immunity of an Inactivated Bluetongue (BTV) Serotype 2 Vaccine against a Virulent BTV Serotype 2 Challenge in Sheep. Vaccine, 27, 2789-2793.

http://www.sciencedirect.com/science/article/pii/S0264410X09003715 https://doi.org/10.1016/j.vaccine.2009.02.099

[11] Noad, R. and Roy, P. (2009) Bluetongue Vaccines. Vaccine, 27, D86-D89. http://www.sciencedirect.com/science/article/pii/S0264410X09012122 https://doi.org/10.1016/j.vaccine.2009.08.037

[12] Savini, G., Hamers, C., Conte, A., Migliaccio, P., Bonfini, B. and Teodori, L. (2009) Assessment of Efficacy of a Bivalent BTV-2 and BTV-4 Inactivated Vaccine by Vaccination and Challenge in Cattle. Veterinary Microbiology, 133, 1-8. http://www.sciencedirect.com/science/article/pii/S0378113508002149 https://doi.org/10.1016/j.vetmic.2008.05.032

[13] Savini, G., MacLachlan, N.J., Sanchez-Vizcaino, J.M. and Zientara, S. (2008) Vaccines against Bluetongue in Europe. Comparative Immunology, Microbiology and Infectious Diseases, 31, 101-120.

http://www.sciencedirect.com/science/article/pii/S0147957107000707 https://doi.org/10.1016/j.cimid.2007.07.006

[14] Gethmann, J., Hüttner, K., Heyne, H., Probst, C., Ziller, M., Beer, M., Hoffmann, B., Mettenleiter, T.C. and Conraths, F.J. (2009) Comparative Safety Study of Three Inactivated BTV-8 Vaccines in Sheep and Cattle under Field Conditions. Vaccine, 27, 4118-4126. http://www.sciencedirect.com/science/article/pii/S0264410X09006380 
https://doi.org/10.1016/j.vaccine.2009.04.072

[15] Savini, F., Monaco, P., Calistri, G., Panichi, A., Ruiu, A. and Leone, V.C. (2004) Neutralising Antibody Response in Cattle after Vaccination with Monovalent Modified-Live Vaccine against Bluetongue Virus Serotype 2. Veterinaria Italiana, 40, 668-670. http://europepmc.org/abstract/med/20422609

[16] Alexandra, H., Nicole, G., Carola, S.L., Antonie, N.J., Harald, L. and Mathias, B. (2012) A Two Year BTV-8 Vaccination Follow Up: Molecular Diagnostics and Assessment of Humoral and Cellular Immune Reactions. Veterinary Microbiology, 154, 247-256. http://www.sciencedirect.com/science/article/pii/S0378113511004159 https://doi.org/10.1016/j.vetmic.2011.07.019

[17] Ramakrishnan, M.A., Pandey, A.B., Singh, K.P., Singh, R., Nandi, S. and Mehrotra, M.L. (2006) Immune Responses and Protective Efficacy of Binary Ethylenimine (BEI)-Inactivated Bluetongue Virus Vaccines in Sheep. Veterinary Research Communications, 30, 873-880. http://link.springer.com/article/10.1007\%2Fs11259-006-3313-5?LI=true https://doi.org/10.1007/s11259-006-3313-5

[18] Huismans, H., van der Walt, N.T., Cloete, M. and Erasmus, B.J. (1987) Isolation of a Capsid Protein of Bluetongue Virus That Induces a Protective Immune Response in Sheep. Virology, 157, 172-179. http://www.sciencedirect.com/science/article/pii/0042682287903266 https://doi.org/10.1016/0042-6822(87)90326-6

[19] Hawkes, R.A., Kirkland, P.D., Sanders, D.A., Zhang, F., Li, Z., Davis, R.J. and Zhang, N. (2000) Laboratory and Field Studies of an Antigen Capture ELISA for Bluetongue Virus. Journal of Virological Methods, 85, 137-149. http://www.sciencedirect.com/science/article/pii/S0166093499001640 https://doi.org/10.1016/S0166-0934(99)00164-0

[20] Reed, L.J. and Muench, H. (1938) A Simple Method of Estimation Fifty Percent End Points. American Journal of Epidemiology, 27, 493-497. http://aje.oxfordjournals.org/content/27/3/493.short

[21] Hofmann, M., Griot, C., Chaignat, V., Perler, L. and Thür, B. (2008) Bluetongue Disease Reaches Switzerland. Schweiz Arch Tierheilkd, 150, 49-56. (In German) http://www.ncbi.nlm.nih.gov/pubmed/18369049 https://doi.org/10.1024/0036-7281.150.2.49

[22] Channakeshava, S.U., Karam, P.S., Awadh, B.P., Rabindra, P.S. and Roopa, H.N. (2010) Cell-Mediated Immune Response and Cross-Protective Efficacy of Binary Ethylenimine-Inactivated Bluetongue Virus Serotype-1 Vaccine in Sheep. Vaccine, 28, 2522-2531. http://www.sciencedirect.com/science/article/pii/S0264410X1000071X https://doi.org/10.1016/j.vaccine.2010.01.039

[23] Takamatsu, H. and Jeggo, M.H. (1989) Cultivation of Bluetongue Virus-Specific Ovine T Cells and Their Cross-Reactivity with Different Serotype Viruses. Immunology, 66, 258-263. http://www.ncbi.nlm.nih.gov/pmc/articles/PMC1385097/

[24] Maan, S., Maan, N.S., Samuel, A.R., Rao, S., Attoui, H. and Mertens, P.P. (2007) Analysis and Phylogenetic Comparisons of Full-Length VP2 Genes of the 24 Bluetongue Virus Serotypes. Journal of General Virology, 88, 621-630. http://jgv.microbiologyresearch.org/content/journal/jgv/10.1099/vir.0.82456-0 https://doi.org/10.1099/vir.0.82456-0

[25] Stott, J.L., Osburn, B.I. and Barber, T.L. (1979) The Current Status of Research on 
an Experimental Inactivated Bluetongue Virus Vaccine. Annual Meeting of the United States Animal Health Association, 55-62.

https://ucdavis.pure.elsevier.com/en/publications/the-current-status-of-research-on -an-experimental-inactivated-blu

[26] Jeggo, M.H., Wardley, R.C. and Brownlie, J.A. (1984) A Study of the Role of CellMediated Immunity in Bluetongue Virus Infection in Sheep, Using Cellular Adoptive Transfer Techniques. Immunology, 52, 403-410.

http://www.ncbi.nlm.nih.gov/pmc/articles/PMC1454488/

[27] Van Maanen, C. and Terpstra, C. (1990) Quantification of Intact 146S Foot-andMouth Disease Antigen for Vaccine Production by a Double Antibody Sandwich ELISA Using Monoclonal Antibodies. Biologicals, 18, 315-319.

http://www.sciencedirect.com/science/article/pii/104510569090036Y

https://doi.org/10.1016/1045-1056(90)90036-Y

\section{Submit or recommend next manuscript to SCIRP and we will provide best service for you:}

Accepting pre-submission inquiries through Email, Facebook, LinkedIn, Twitter, etc.

A wide selection of journals (inclusive of 9 subjects, more than 200 journals)

Providing 24-hour high-quality service

User-friendly online submission system

Fair and swift peer-review system

Efficient typesetting and proofreading procedure

Display of the result of downloads and visits, as well as the number of cited articles

Maximum dissemination of your research work

Submit your manuscript at: http://papersubmission.scirp.org/

Or contact wjv@scirp.org 